intervenientes ou não, os que se interessam pelas organizações produtivas. $\mathrm{E}$, tal como o faz a revista Fortuna, já aqui citada - precisamente referindo-se, entre outras, à obra que aqui nos ocupa -, lamentar que obras desta valia e importância acabem por ser lidas apenas por uns tantos eleitos, sem as repercussões científicas e práticas a que tinham, por mérito próprio, direito.

António Rafael Amaro

\title{
O "RELATÓRIO PORTER" E A COMPETITIVIDADE DAS EMPRESAS PORTUGUESAS
}

Um conjunto de quarenta e uma empresas e seis entidades públicas encomendou à "Monitor Company" - empresa liderada pelo Professor Michael Porter, especializada em "competitividade" e conhecida pela sua colaboração com empresas e governos de muitos países - , um estudo com o objectivo de "Construir as vantagens competitivas de Portugal". O projecto conta com a colaboração da ESFI (uma empresa de consultadoria estratégica) e envolve um significativo número de investigadores e especialistas, ligados à Universidade Católica e à Associação Industrial Portuense. Uma comissão directiva, composta por oito elementos (Eng. Luís Todo Bom, Prof. Ricardo Bayão Horta, Dr. António Carrapatoso, Dr. João Oliveira Rendeiro, Eng. Alberto Moreno, Dr. João Salgueiro, Prof. Fernando Freire de Sousa e Eng. Mário Pais de Sousa), "assegura a orientação de "topo" à estrutura e forma do projecto". Como sublinha a referida comissão directiva, na nota de apresentação do documento publicado [Monitor Company, A Competitividade de Portugal: desenvolver a autoconfiança, Sep. Exame, Set. de 1993, 26 p.], trata-se de um "projecto inédito em Portugal pelas características de aprofundamento do significado do novo paradigma nos clusters e políticas", visando aumentar a competitividade das empresas portuguesas. Trata-se, efectivamente, de uma radiografia da situação económica do nosso país, um poderoso instrumento de trabalho para todos os cientistas sociais.

A encomenda desse estudo resulta da preocupação com o abrandamento da forte taxa de crescimento económico registada nos últimos anos ("o crescimento real do PIB reduziu-se para 1,1\% em 1992, quando em 1989 era de 5,5\%") e com a sensação geral de se "andar à deriva", sensação sentida pela equipa de Michael Porter nas diversas discussões com "cerca de uma centena de líderes da sociedade e da economia portuguesas". Ainda que a situação do País reflicta a dimensão e características da recessão mundial, as raízes dessa quebra do crescimento económico nacional parecem ser sobretudo de natureza estrutural. Assim, face à perti- 
nente pergunta: "E agora para onde deve Portugal ir?", urge encontrar a(s) resposta(s).

A primeira fase do projecto (Audito de competitividade) - que o documento apresentado sumaria - procede "a um levantamento da competitividade das empresas portuguesas, examina o contexto (política governamental, educação, etc.) em que cada empresa opera e realça os estrangulamentos críticos à competitividade futura". A segunda fase (Iniciativas de acção), em curso, até Janeiro de 1994, irá "potenciar um ambiente favorável à mudança no país, concentrando-se nos pontos-chave salientados no diagnóstico".

Aguardado com enorme expectativa, realizado num clima de colaboração franca e aberta, o estudo da equipa dirigida pelo professor da Harvard Business School está a gerar uma inusitada e acalorada discussão nas empresas, universidades, associações empresariais, imprensa especializada e nos círculos governamentais. As opiniões dividem-se. Agora que são conhecidos os resultados preliminares do projecto, poucos parecem ser os que vêem com entusiasmo as conclusões do relatório. Elisa Guimarães Ferreira, vice-presidente da Associação Industrial Portuense, classificou o momento como "um processo de viragem na política industrial portuguesa, com a consciência de que a questão da tecnologia é a da sua aplicação à produção e não a do desenvolvimento da tecnologia pela tecnologia" (L. Bessa, Público/Economia, 1993.09.20, p. 17). A maioria dos observadores pronunciou-se, face às conclusões do relatório, ou com cepticismo ou com indisfarçado agastamento, procurando minimizar o seu impacte estratégico e os efeitos da sua divulgação.

Os cépticos, o grupo mais numeroso, encontraram numa expressão do Ministro da Indústria o desabafo que lhes faltava: o estudo "não é uma bíblia". Ainda recentemente, Lopes dos Santos, achando que o relatório é importante, sobretudo, "porque nos dá informação, mais dados e expõe-nos um modelo, como que um "paradigma" a estudar, melhorar e, possivelmente, adaptar", acaba por concluir - citando Mira Amaral - que o "Relatório Porter" não é nenhuma bíblia", porque, "para recuperar a nossa economia e a nossa indústria não basta fazer exclusivamente o que lá se diz" (Vida Económica, 446, 1993.10.22, p. 13).

O outro grupo - constituído pelos sectores 'excluídos' da seleç̧ão de clusters - teme "pelos efeitos perversos do relatório na dinâmica de aplicação dos fundos comunitários". Estão desse lado, entre outros, o lobby das celuloses (que se acha preterido em favor do das madeiras), bem como muitos dos que apostaram forte nas "novas tecnologias", devido ao relevo concedido, no relatório, às actividades tradicionais, desde que redimensionadas, reorganizadas e apoiadas pelas altas tecnologias (por esse motivo, torna-se pertinente a leitura da obra de Jaime Reis, O atraso económico Português. 1850-1930, Lisboa, IN-CM, 1993). 
No entanto, como afirma Daniel Amaral, se outra utilidade não tivesse, "a equipa de Michael Porter teve para já um mérito: pôs as pessoas a pensar" (Fortuna, 20, Nov. de 1993, p. 80). O debate está lançado!

Logo na "Introdução", os seus autores sublinham que "este relatório de progresso apresenta um novo paradigma para a abordagem das questões de competitividade em Portugal. Baseia-se na necessidade de identificar e desenvolver o que é único em Portugal, em vez de imitar as estratégias de outros países". Metodologicamente, recusam "as soluções clássicas, desajustadas, que buscam a salvação do país na "política macroeconómica", ou em "aumentos de escala", ou em "alta tecnologia". Portugal - concluem - "não poderá buscar a excelência tentando competir através de vias que foram bem sucedidas no século XX - Portugal "perdeu já o comboio" deste século e os seus competidores possuem uma vantagem de partida de décadas".

Mas antes de nos debruçarmos sobre o "novo paradigma de competitividade nacional" proposto por Porter e pela sua equipa, vejamos as linhas mestras do "paradigma existente", construído ao longo de inúmeras entrevistas com os líderes de opinião seleccionados, ligados à indústria, universidades, entidades públicas, associações, imprensa e observadores internacionais. Trata-se de um conjunto de postulados e princípios "coerentes quando considerados a nível de um modelo microeconómico e bem sustentados pela teoria económica clássica"; no entanto, salienta a "Monitor Company", "infelizmente, muitos desses princípios apresentam deficiências ou, quando não é esse o caso (por exemplo, na necessidade de melhorar a educação), são notórias as suas reduzidas capacidades de acção". Atentemos nos tópicos desse 'retrato' consensual e na argumentação da equipa de Michael Porter:

- Portugal necessita de identificar os sectores que são estratégicose direccionar os recursos para onde são mais necessários - diz-se. "A escolha de vencedores provou ser uma experiência com elevados erros e custos".

- Portugal necessita de desenvolver as indústrias de tecnologia de ponta. "Essas indústrias - especialmente a robótica - são notoriamente não rentáveis".

- A base industrial de Portugal é demasiado estreita. Muitos países (como a Dinamarca e a Suíça) "asseguram uma larga proporção das suas exportações com base num número relativamente reduzido de sectores".

- Portugal necessita de dispor de algumas grandes empresas que possam ser os motores do crescimento. Argumento deficiente porque "uma escala elevada não representa uma garantia de rentabilidade - basta observar os exemplos recentes da General Motors, 
IBM e Philips". Assim, "a ausência de grandes empresas deveria ser vista como uma vantagem".

- Os gestores portugueses apresentam deficiências em aptidões básicas, especialmente em "marketing". "Estamos de acordo. Mas temos de ir além das meras afirmações [...]. As empresas têm de ser encorajadas a participar em mercados exigentes". Diferente é a apreciação a propósito do envolvimento da Simoldes com a Renault, em França, e do negócio de autocarros de luxo da Salvador Caetano, no Reino Unido.

- Portugal necessita de resolver os seus problemas de infra-estruturas e de "soft infrastructure". "Concordamos igualmente, mas temos de passar à acção. Não podemos esquecer que os verdadeiros desafios apenas se iniciarão uma vez que se encontre instalada a infra-estrutura básica".

- O governo não procedeu tão rápido quanto necessário na prossecução dos objectivos acima descritos, sendo necessário um maior envolvimento do mesmo. Contraposição: "é necessário um novo modelo de mudança no qual a sociedade civil abandone uma posição passiva". Quanto ao governo, pede-se abandone antigos programas e métodos. Um governo "empreendedor", "é inovador, imaginativo e criativo. Assume riscos. Transforma funções geradoras de receitas, em vez de consumidoras de orçamentos [...]. Coopera com o sector privado [...]. Privatiza. Cria empresas geradoras de receitas. É orientado para o mercado. Concentra-se na mediação da performance. Recompensa o mérito".

A globalização económica actual inviabiliza o paradigma tradicional, que assentava em factores custos. Em vez da competitividade assente em baixos custos (de mão-de-obra e matérias-primas), a equipa de Porter propõe, como elemento dinâmico do seu modelo, a noção de produtividade, definida "como o valor de produção correspondente ao total de dias de trabalho e de capital investido". Uma das dimensões do "Diamante de Porter" é, precisamente, a defesa do agrupamento das empresas em clusters. "Os clusters são característicos de economias muito avançadas", e "são grupos de entidades cujas interrelações reforçam a vantagem competitiva; os clusters envolvem sectores fornecedores, sectores clientes e sectores relacionados que são competitivos".

E, na medida em que "são as empresas que competem e não os países", "a produtividade não é tanto uma função dos sectores em que um país compete, mas como competem as empresas nesses sectores". 
Por outro lado, acrescentam, “a elevada produtividade não se restringe a sectores de elevada tecnologia, podendo igualmente ser obtida em sectores industriais tradicionais e em serviços".

E aqui chegamos à dimensão mais contestada e polémica (?) do Relatório. Uma vez que "nenhum país dispõe de competitividade em todos os sectores", "o sucesso competitivo de cada país encontra-se concentrado em certos sectores e grupos de sectores inter-relacionados, designados por clusters". E acrescentam que "os países tendem a ser bem sucedidos num número reduzido de clusters ou sectores inter-relacionados". Ora, em Portugal, "as 50 maiores exportações representam mais de $20 \%$ do total, encontrando-se altamente concentradas em dois grandes clusters, os têxteis, vestuário e os produtos florestais".

Assim, as empresas, nesses clusters, podendo dispor de "uma clara base doméstica, que constitua o centro da sua investigação, a massa crítica da sua produção sofisticada e o centro nevrálgico das suas decisões estratégicas", têm de "competir a nível global". Devem "contratar matérias-primas e capitais nos mercados que apresentam melhores preços, bem como transferir actividades para outras regiões a nível mundial, por forma a obter baixos custos de mão-de-obra para funções com menos requisitos em termos de aptidões, ou ganhar acesso a mercados estrangeiros e poder recorrer a certas tecnologias".

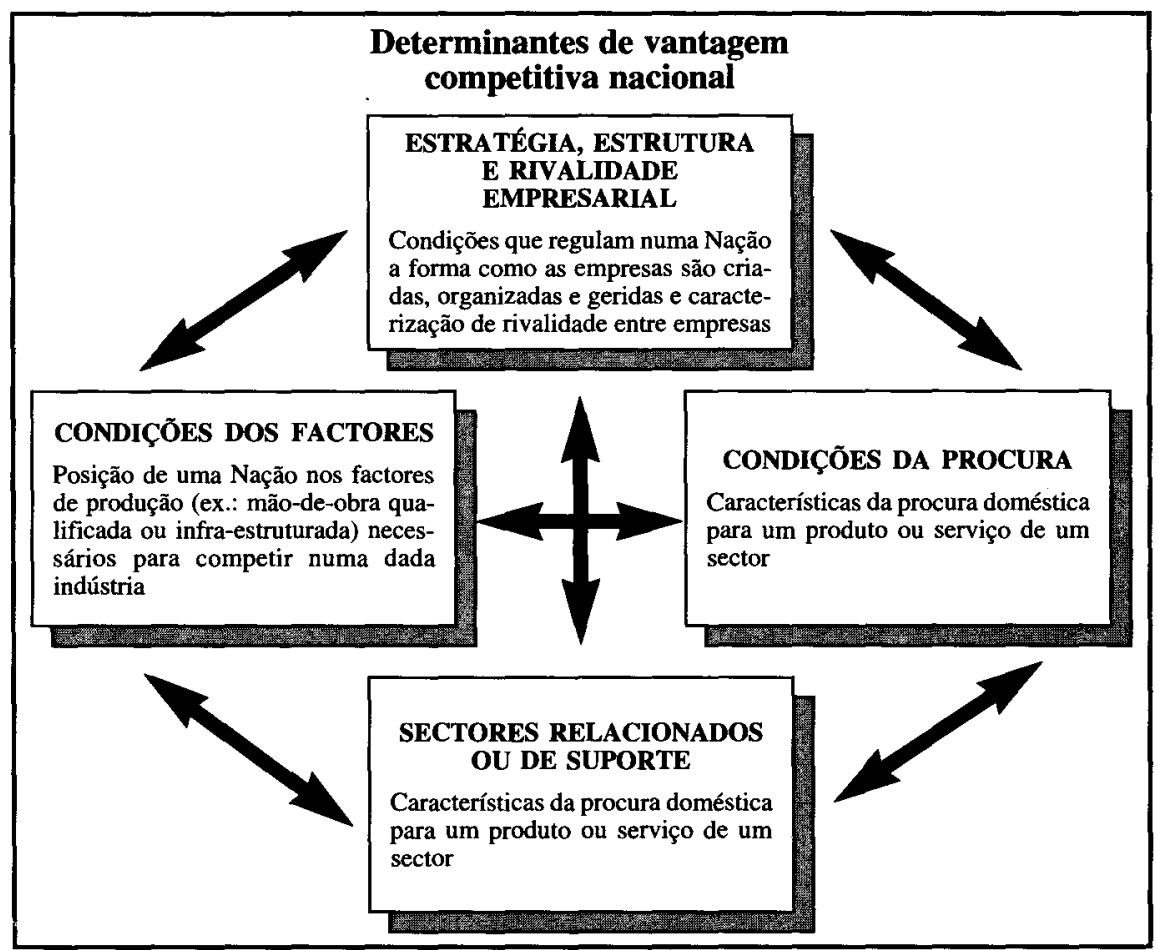


O "Diamante de Porter", o "diamante da vantagem competitiva" — sistema basilar de toda a estratégia defendida - define os atributos que desempenham o papel principal na competitividade. Convém sublinhar a advertência dos autores do relatório, que se trata de "um sistema dinâmico que é mais importante que a soma da suas partes", e é sintetizado em seis pontos: a) O diamante constitui um sistema; $b$ ) Os determinantes do diamante reforçam-se mutuamente; $c$ ) As empresas competitivas estão sediadas em "bases domésticas" com ambientes dinâmicos; d) As empresas competitivas operam em "clusters"; $e$ ) A vantagem competitiva é inerente à base local; $f$ ) $\mathrm{O}$ governo pode desempenhar um papel positivo.

1. As condições dos factores de uma Nação "constituem os inputs base da concorrência", e podem ser agrupados em quatro tipos:
A. factores físicos;
B. factores financeiros;
C. factores de conhecimento;
D. factores humanos.

Adicionalmente, são distinguidos os factores básicos dos avançados (os mais escassos e valiosos), os generalizados (que possuem valor para um conjunto largo de sectores) dos especializados (que apenas têm valor para um sector específico).

Assim, no século XXI, os papéis dos factores serão diferentes:

a) "Os factores avançados estão a tornar-se progressivamente mais importantes que os factores básicos".

b) "Por razões similares, os factores especializados estão a tornar-se progressivamente mais decisivos para a competição do que os factores generalizados".

c) "O conhecimento e os factores humanos estão a ganhar importância competitiva face aos factores físicos e financeiros".

Esta análise levou a equipa de Porter a concluir que é precisamente "naqueles sectores em que forem melhores na criação de factores que gozarão dos mais elevados níveis de sucesso".

2. Condições da procura. Para lá da defesa de "compradores sofisticados e exigentes", por forma a levar as empresas a "atingir elevados padrões, a inovar e a deslocar-se para segmentos mais avançados", o relatório defende que, "ao contrário do que convencionalmente se pensa, a dimensão do mercado doméstico não constitui um determinante-chave na vantagem competitiva".

3. Estratégia, estrutura e rivalidade empresarial. A "Monitor Company" defende a existência de uma forte rivalidade interna; é que "as empresas muito dificilmente conseguem ser bem sucedidas a nível internacional se não competirem com empresas rivais fortes a nível doméstico e o sucesso não poderá perdurar no longo prazo se a rivalidade se extinguir". 
4. Sectores relacionados e de suporte. A equipa de Michael Porter defende um inter-relacionamento estreito entre fornecedores e consumidores, possibilitando às empresas "a oportunidade de influenciar os esforços técnicos dos seus fornecedores, podendo constituir-se como locais de testes para a área I\&D, acelerando assim o ritmo de inovação".

Aguarda-se a conclusão da Fase 2 desse projecto, que consagra o "modelo de acção", bem como o relatório final, "um extenso relatório, em preparação, que descreve as análises e os resultados". É que, como os seus autores realçaram, "mesmo em ocasiões em que o diagnóstico nacional foi bem conduzido, como na questão da gestão florestal, os resultados foram limitados", ou a mudança não se operou com a celeridade desejável. As razões dessa limitada passagem à acção serão:

- A falta de uma visão sistémica.

- Uma excessiva dependência da sociedade civil face ao governo e instituições públicas.

- Uma tendência para concentrar as reformas ao nível da oferta.

Nessa medida, e dado que a "Monitor Company" verificou existirem "enormes diferenças de questões competitivas entre grandes sectores de actividade, foram desenvolvidos processos independentes de definição de prioridades a nível da agricultura, indústria e serviços". Assim, o processo de abordagem analítica de tratamento dos clusters processa-se em cinco etapas e visará, fundamentalmente, seleccionar "os clusters com base na sua representatividade", difusão "da abordagem através do desenho de um mecanismo de transferência" e, por fim, dar prioridade à "acção sobre a análise":

1. Pesquisa alargada.

2. Identificação de questões-tipo.

3. Selecção de um número limitado de iniciativas para a acção.

4. Análise detalhada.

5. Concepção de mecanismos de transferência.

Dada a importância dessa fase do estudo - conexa com a defesa do "primado da acção sobre a análise" - , para uma avaliação global da justeza das propostas estratégicas da "Monitor Company", e uma vez que o documento em análise mais não visa do que apresentar a abordagem dessa equipa, ao desenvolvimento da competitividade em Portugal, ficamos por aqui com a promessa de regressarmos com uma análise exaustiva e integrada do "Relatório Porter", sendo possível, então, uma avaliação da receptividade e do sucesso do número limitado de iniciativas para a acção em curso. 